\title{
C-reactive protein for rapid diagnosis of infection in leukaemia
}

\author{
P. H. MACKIE, R. A. CROCKSON, AND J. STUART \\ From the Department of Immunology, University of Birmingham, and the Department of Haematology, \\ Queen Elizabeth Hospital, Birmingham B15 2TH, UK
}

SUMMARY C-reactive protein, measured in serum from 38 patients with leukaemia, was elevated to at least $100 \mathrm{mg} / \mathrm{l}$ at the beginning of 32 of 34 episodes of infection, and subsequently rose above $100 \mathrm{mg} / \mathrm{l}$ in all 34. Uninfected patients, whether in leukaemic remission or relapse and whether pyrexial or not, always had levels below $100 \mathrm{mg} / \mathrm{l}$, with four exceptions out of 290 measurements. Estimation of two other acute-phase proteins, $\alpha_{1}$-antitrypsin and orosomucoid, was not of additional diagnostic value. Serial measurement of C-reactive protein may be important for the early detection of infection in the leukaemic patient with neutropenia.

Infection is a common cause of death in acute leukaemia. Its early detection is difficult, however, since clinical signs are often masked by neutropenia, and bacteriological culture usually requires 24 hours. Rapid screening tests for infection, such as neutrophil cytochemistry or the Limulus test for endotoxaemia, have not yet proved sufficiently reliable when applied to the individual patient (Martinez-G et al., 1973, Steigbigel et al., 1974; Mackie et al., 1979).

The acute-phase protein response to infection is rapid enough to be of potential value as a screening test, since the level of C-reactive protein (C-RP) may rise some 6 hours after an acute stimulus (Kushner and Broder, 1972; Yen-Watson and Kushner, 1974). If this early rise occurs reliably in response to infection, then serial measurement would be of potentially greater clinical value than bacteriological culture for early diagnosis. The present study was therefore designed to assess the value of three acute-phase proteins (C-RP, $\alpha_{1-}$ antitrypsin, and orosomucoid) as screening tests for infection in leukaemia.

\section{Patients and methods}

Thirty-eight patients with leukaemia (20 acute myeloblastic, five chronic granulocytic, six acute lymphoblastic, and seven chronic lymphocytic) were studied. Blood was taken at outpatient

Received for publication 14 June 1979 attendances when the patients were also examined for clinical signs of infection and samples were taken for bacteriological culture when relevant. Blood samples from inpatients were taken at least three times a week with additional specimens during pyrexia. Inpatients were examined for infection at least once daily, and samples for culture were taken whenever infection was suspected; in addition, swabs from the nose, throat, axillae, and perineum were cultured at least weekly.

Patients with a clinical diagnosis of infection were divided into two groups: patients from whom pathogens could not be isolated on microbiological culture, and patients with microbiological confirmation of infection. Patients with neither clinical nor microbiological evidence of infection were grouped into those in leukaemic remission and those in relapse.

Blood samples were centrifuged, and the serum was stored at $4^{\circ}$ in sterile containers to which molar sodium azide solution $(0.05 \mathrm{ml}$ per $5 \mathrm{ml}$ serum) had been added. Levels of C-RP, $\alpha_{1}$-antitrypsin, and orosomucoid were subsequently measured by radial immunodiffusion (Mancini et al., 1965) using commercial antisera (Seward Immunostics) for $\alpha_{1}$-antitrypsin and orosomucoid and an antiserum raised to purified human C-RP. The latter antigen was isolated from human ascitic fluid, by a modification of the method of Hokama and Riley (1963), followed by gel filtration on Sephadex G-200 and then concentrated to give a reference preparation. This material was used in rabbits to raise an anti- 
serum which was treated with solid-phase human serum immunoabsorbent to ensure monospecificity. A secondary human serum C-RP standard, equivalent to $62.5 \mathrm{mg} / \mathrm{l}$, was calibrated against the reference preparation. In the radial immunodiffusion method, a calibration curve (range $12 \cdot 5-62.5 \mathrm{mg} / \mathrm{l}$ ) was prepared using $10 \mu \mathrm{l}$ aliquots of secondary standard.

\section{Results}

There were 17 episodes in which a diagnosis of infection was clear on clinical grounds but from which material for microbiological culture either could not be obtained or yielded no pathogens as a result of previous antibiotic therapy. These episodes included chest infection (7) and cellulitis and/or tissue necrosis (10). In a further 17 episodes of infection, positive cultures were obtained (Table). The level of acute-phase proteins in the first blood sample obtained during each infective episode, together with the levels found in uninfected patients, are shown in Figures 1-3.

Table 17 culture-positive episodes of infection

\begin{tabular}{lll}
\hline Site & Organism & No. of episodes \\
\hline Blood & Escherichia coli & 1 \\
& Bacteroides sp. & 1 \\
Upper respiratory & Pseudomonas aeruginosa & 1 \\
tract & B-haemolytic streptococcus & 3 \\
& Streptococcus viridans & 1 \\
& Streptococcus faecalis & 1 \\
Lower respiratory & Cabsiella sp. & 1 \\
tract & Streptococcus pneumoniae & 1 \\
Urinary tract & Klebsiella sp. & 1 \\
Thigh abscess & Pseudida albicans & 2 \\
Facial vesicles & Staphylococcus aureus & 1 \\
& Herpes simplex & 1 \\
& Total & 17 \\
\hline
\end{tabular}

Levels of $\alpha_{1}$-antitrypsin at the beginning of the 34 episodes of infection, whether confirmed microbiologically or not, were significantly higher $(P<$ 0.001, Kolmogorov-Smirnov two-sample test (Siegel, 1956)) than the levels for all uninfected patients whether in leukaemic remission or relapse (115 observations) (Fig. 1). There was considerable overlap, however, some levels at the beginning of infection falling within the normal range.

For orosomucoid (Fig. 2), levels at the beginning of infection were again significantly higher $(P<$ 0.001 ) than in uninfected patients. The first value obtained in each infective episode was always, with one exception, elevated above the normal range, but there was still considerable overlap between the groups.

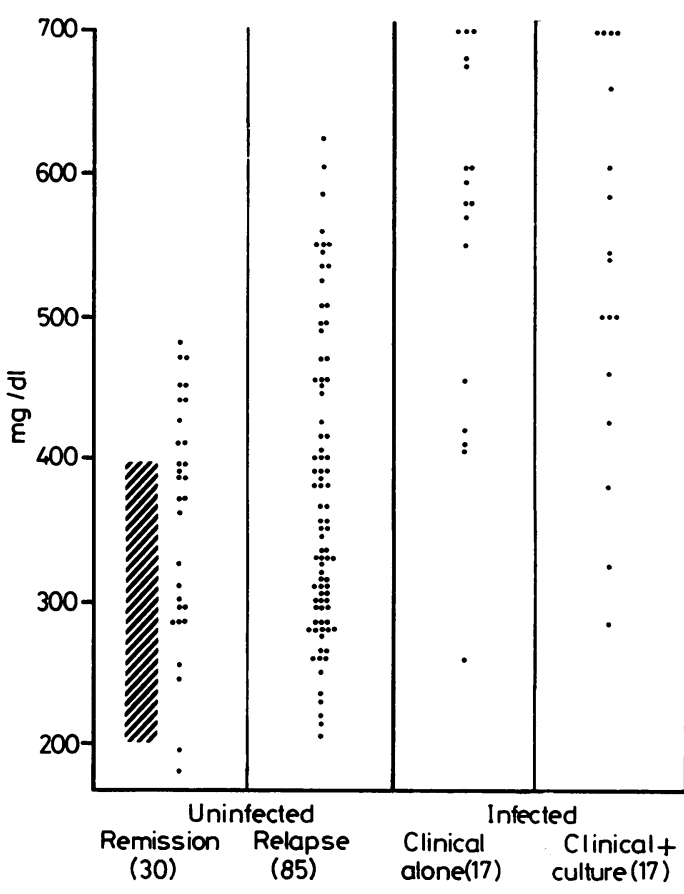

Fig. 1 Individual values for $\alpha_{1}$-antitrypsin in uninfected and infected patients. Number of estimations in parentheses. Normal range shown by hatching.

For C-RP, however, there was minimal overlap between infected and uninfected patients (Fig. 3). The latter, whether in leukaemic remission or relapse, had C-RP levels below $100 \mathrm{mg} / \mathrm{l}$, with only four exceptions out of 290 measurements; the maximum C-RP level was $110 \mathrm{mg} / \mathrm{l}$. C-RP levels showed no correlation with the degree of peripheral blood leucocytosis (in chronic leukaemia) or blast cell count (in acute leukaemia). C-RP was measured more frequently than the other two acute-phase proteins to confirm lack of overlap between infected and uninfected patients. Conversely, in infection, levels of $100 \mathrm{mg} / 1$ or above were obtained in the first blood specimen taken, with only two exceptions out of 34 infective episodes. In both of these cases C-RP levels exceeded $100 \mathrm{mg} / \mathrm{l}$ on the next day. Resolution of infection was accompanied by a fall in the C-RP level over three to four days.

\section{Discussion}

This study suggests that a C-RP level above $100 \mathrm{mg} / 1$ may be a useful early indicator of infection in leukaemic patients. There is an interval of about 6 hours between a stimulus, such as the onset of acute inflammation or infection, and elevation of C-RP 


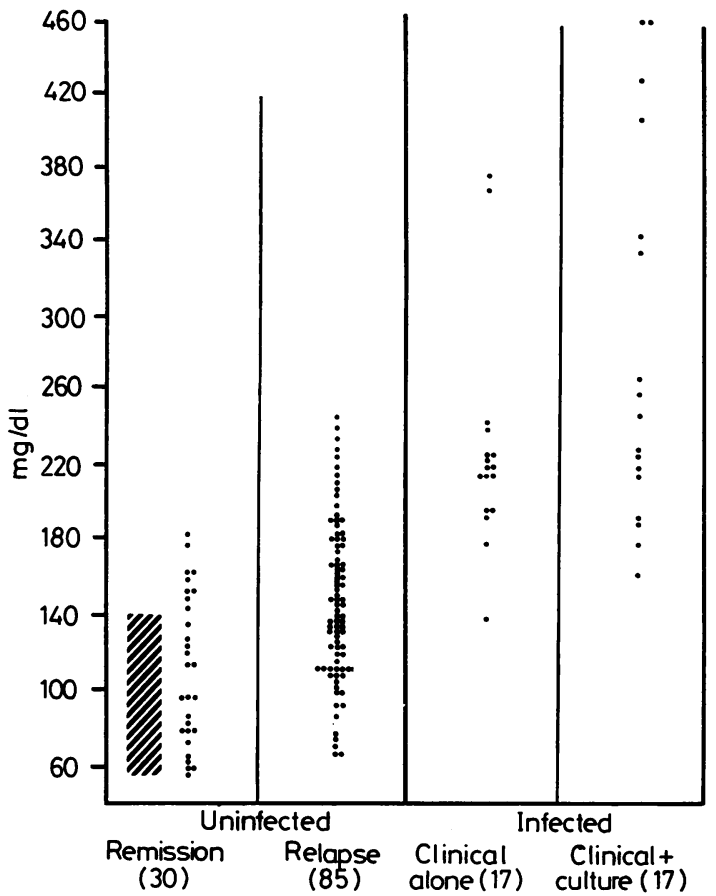

Fig. 2 Individual values for orosomucoid in uninfected and infected patients. Number of estimations in parentheses. Normal range shown by hatching.

Rapport et al., 1957; Yen-Watson and Kushner, 1974). Nevertheless, in our study, the first serum sample taken in each infective episode had a C-RP level that was nearly always elevated above $100 \mathrm{mg} / \mathrm{l}$. Presumably there is a latent period of several hours between the onset of infection and the development of clinical signs, C-RP levels increasing significantly during this interval. The exact time sequence for the development of pyrexia, clinical evidence of infection, and elevation of C-RP above $100 \mathrm{mg} / \mathrm{l}$ requires to be determined by prospective study. Peak levels of C-RP were not attained until at least 24 hours from the time of the initial blood specimen, and, during this period, other objective data supporting a diagnosis of infection, such as positive microbiological cultures or typical radiological features, usually became available.

C-RP levels are probably raised in any inflammatory process, whether infective or not. It is unlikely that the coexistence of a subclinical inflammatory disease would cause a diagnostically confusing elevation in C-RP level. In a study of 187 patients with rheumatoid arthritis, McConkey et al. (1972) showed that the level of C-RP exceeded $100 \mathrm{mg} / \mathrm{l}$ only in those patients with severe disease, which would be evident clinically. Many of our

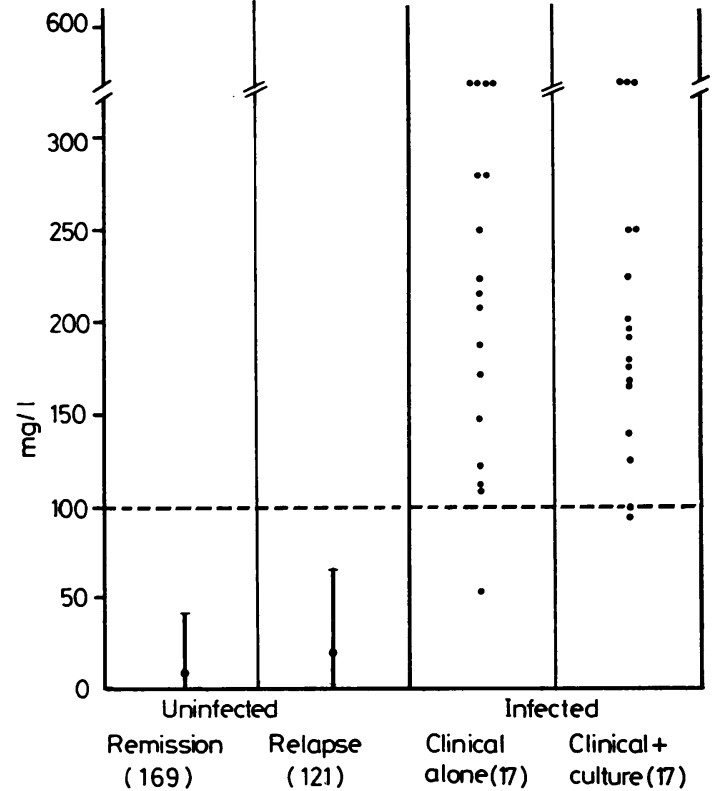

Fig. 3 Mean values $\pm 2 S D$ for $C-R P$ in uninfected patients and individual values in infected patients.

Number of estimations in parentheses. Normal range $0-10 \mathrm{mg} / \mathrm{l}$.

uninfected patients were receiving cytotoxic drugs, antibiotics, or blood products, which were followed in some cases by pyrexia and rigors. Nevertheless, with four exceptions out of 290 measurements, these patients had C-RP levels below $100 \mathrm{mg} / \mathrm{l}$. The acute-phase response to infection, however, was quantitatively much greater and also occurred in those infected patients whose inflammatory response was clinically masked by severe neutropenia. Measurement of $\alpha_{1}$-antitrypsin and orosomucoid, which are not elevated until 24-48 hours after an acute stimulus (Crockson et al., 1966; Werner, 1969), gave no additional information.

C-RP was measured by radial immunodiffusion with a between-batch variability of $10 \%$; a level of 90-110 mg/l may therefore be regarded as equivocal evidence of infection. This protein may alternatively be measured within an hour by laser nephelometry, and a preliminary study by us on 87 sera has shown good correlation $(r=0.964)$ with the 18-hour radial immunodiffusion technique. Daily monitoring of C-RP by laser nephelometry may therefore provide a rapid test for infection in the neutropenic, leukaemic patient and thereby guide the use of antibiotics and granulocyte transfusions. Daily measurement of C-RP may also prove to be of diagnostic value in patients whose blood levels have 
substantially increased but are still below the diagnostic level of $100 \mathrm{mg} / \mathrm{l}$.

We are indebted to A. J. Davies, S. R. Heller, P. C. W. Stone, and P. Winarso for assistance with this study, and to the Leukaemia Research Fund for financial support.

\section{References}

Crockson, R. A., Payne, C. J., Ratcliff, A. P., and Soothill, J. F. (1966). Time sequence of acute phase reactive proteins following surgical trauma. Clinica Chimica Acta, 14, 435-441.

Hokama, Y., and Riley, R. F. (1963). Purification of c-reactive protein, an acute phase protein of human serum. Biochemica et Biophysica Acta, 74, 305-308.

Kushner, I., and Broder, M. I. (1972). Serum CRP kinetics in acute myocardial infarction (Abstract). Clinical Research, 20, 794.

McConkey, B., Crockson, R. A., and Crockson, A. P. (1972). The assessment of rheumatoid arthritis. Quarterly Journal of Medicine, 41, 115-125.

Mackie, P. H., Mistry, D. K., Wozniak, J. T., Dodds, W. N., Geddes, A. M., and Stuart, J. (1979). Neutrophil cytochemistry in bacterial infection. Journal of Clinical Pathology, 32, 26-30.
Mancini, G., Carbonara, A. O., and Heremans, J. F. (1965). Immunochemical quantitation of antigens by single radial immunodiffusion. Immunochemistry, 2 , 235-254.

Martinez-G, L. A., Quintiliani, R., and Tilton, R. C. (1973). Clinical experience on the detection of endotoxemia with the Limulus test. Journal of Infectious Diseases, 127, 102-105.

Rapport, M. M., Schwartz, A. E., and Graf, L. (1957). C-reactive protein in patients following operation. Annals of Surgery, 145, 321-325.

Siegel, S. (1956). Non-parametric Statistics for the Behavioral Sciences, pp. 127-136. McGraw-Hill, New York.

Steigbigel, R. T., Johnson, P. K., and Remington, J. S. (1974). The nitroblue tetrazolium reduction test versus conventional hematology in the diagnosis of bacterial infection. New England Journal of Medicine, 290, 235-238.

Werner, M. (1969). Serum protein changes during the acute phase reaction. Clinica Chimica Acta, 25, 299-305.

Yen-Watson, B., and Kushner, I. (1974). Rabbit CRP response to endotoxin administration: dose-response relationship and kinetics. Proceedings of the Society for Experimental Biology and Medicine, 146, 1132-1136.

Requests for reprints to: Professor J. Stuart, Department of Haematology, Queen Elizabeth Hospital, Birmingham B15 2TH, UK. 